\title{
Chronological Experience of Alice in Wonderland-Like Visual Impairment Due To Correlating Physical Abuse till Teenager Age
}

\author{
Bittmann S*, Alieva EM, Villalon G and Luchter E \\ Department of Pediatrics, Ped Mind Institute, Medical and Finance Center Epe, Germany
}

ISSN: 2576-9200

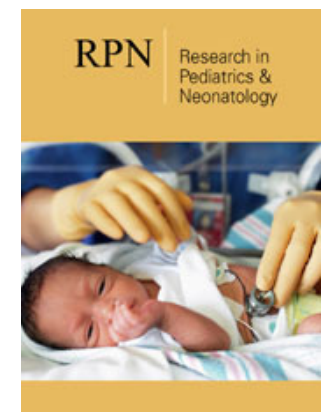

*Corresponding author: Bittmann S, Department of Pediatrics, Ped Mind Institute (PMI), Germany

Submission: 地 June 11, 2020

Published: 酸July 31, 2020

Volume 4 - Issue 4

How to cite this article: Bittmann S, Alieva EM, Villalon G, Luchter E. Chronological Experience of Alice in Wonderland-Like Visual Impairment Due To Correlating Physical Abuse till Teenager Age. 4(4). RPN. 000594. 2020.

DOI: 10.31031/RPN.2020.04.000594

Copyright@ $@$ Bittmann S. This article is distributed under the terms of the Creative Commons Attribution 4.0 International License, which permits unrestricted use and redistribution provided that the original author and source are credited.
Keywords: Alice in Wonderland; Seizure; Physical abuse; Child

\section{Introduction}

Alice in Wonderland Syndrome (AIWS) was named after Lewis Carroll's description in his novel. It was in 1955 that John Todd, a psychiatrist, first described this entity. Todd described it as "Alice's Adventures in Wonderland" by Lewis Carroll. The author Carroll suffered from severe migraine attacks. Alice in Wonderland Syndrome is a confusing state of seizures that affect visual perception. AIWS is a neurological form of seizures that affect the brain, causing impaired perception. The patients describe visual, auditory and tactile hallucinations and perceptual disorders. The causes of AIWS are not yet known exactly. Cases of migraines, brain tumors, depression episodes, epilepsy, delirium, psychotropic drugs, ischemic stroke, EBV, mycoplasma and malaria infections correlate like seizures with AIWS. Neuroimaging studies show disorders of brain regions including the temporoparietal junction, the temporal lobe and the occipital lobe as a typical localization of the visual pathway.

\section{Case Report}

The individual chronological report was described by a 67 years-old men, who contacted me in early June 2020 from California, USA. An email interview was analyzed and retrospective described as following:

\section{Fever before age 9}

People talking to me sounded like they were speaking really fast. I had the feeling of being upside down. I was at my grandmother's house and was on her red sofa. I found out later that I was not there but, in my own home.

\section{Age 9}

Evening watching T.V. while lying down. Visual perception was like looking through wrong end of binoculars. Everything was push far away only lasted a short time.

\section{Age 15}

While driving at night. Same visual perception as in age 9. Had to pull over because of the distortion. Lasted a few minutes.

\section{Age 21}

During Meditation during the day outside. As I relaxed more the visual perception as in Age 9 happened spontaneously. Even though my eyes were closed I knew IF I opened my eyes I would be seeing through the wrong end of binoculars. Then the body sensations started happening. I was sitting cross legged outside but couldn't feel my body. It was as if I had no body and even though I was outside with the sun shining I was in total darkness. I didn't 
know where or how my body was positioned. Like I was in space and I was a pin point of energy. I felt quiet and at peace. There was a feeling that I could go deeper into the silence but I was hesitant. I became a little frightened because I felt I could stay there forever and not be able to come back out of it. (Now, when you actually look through the wrong end of binoculars it's only a visual thing, you don't feel anything. But in the AIWS I felt a sensation in my eyes. I could feel like a pulling at my temples.) When I became hesitant, I decided I should come out of my meditation. I opened my eyes but the visual perception continued. Everything was still pushed far away. I shook my head and in a few seconds I was back to normal.

\section{Age in early 30's}

Having meditated off and on for years I couldn't go into deep meditation like the yogi's talked about. It was always what I call, surface meditating. I wanted to get that feeling of going into deep meditation and I thought if I can get that visual perception thing going, so I focused on my Pineal gland and my eyes to see if I could bring on the visual perception intentionally and I did, within a few minutes. What I found out was I could only go so deep into the meditation as I did at 21 because the old fear would come back. Getting stuck there. Throughout the following years I tried to break through that fear barrier but, I couldn't. What did happen was that it was harder to get back to normal. The wrong end of binocular vision perception took longer to get back to normal. I don't see them as seizures. But nothing unusual happen before the early episodes. Nothing unusual before the ones I initiated.

\section{Parents}

Father was verbally a physically abusive. He would beat us for insignificant things. Eg. Like not mopping the floor. Mother was passive. Not stopping the abuse. Physical. Whipping with various forms of articles. Belts, a pliable hard rubber belt he crafted, tree branches. (The switch). This is mainly why I kept leaving home. Well, the abuse Started when we were very young I was 5 Years old I think. It could have been earlier but I can't remember. And stopped for me when I left at home at 17 . So there could be a correlation. I have one brother and 3 sisters and none have had my experience. Didn't know the reason till last week. Possible reason. I found out from my Aunt, my mother's sister that my mother didn't like doing any chores around the house. She always had an excuse. Had rheumatic fever and a heart murmur when she was young. Everyone took care of her. The poor baby. After she got better, it was like expected for people to take care of her. Anyway, my Father came from a clean home. At that time it was expected that the wife clean and have food ready when my father got home. It never was. She always had an excuse. Taking care of the babies. So I think my Father resented that and took it out on me and the others. They have other issues. All the basic text book type issues. I ran away from home at 15-16. At 17 I saved money and left home for over a year. Then suddenly in my late 30's, early 40's I couldn't get back into that space intentionally through meditation. I was kind of relieved but also disappointed. I still meditate and can get very relaxed but, I could still feel my body. Other things have happened during and after AIWS episodes but, they are much more stranger and less believable than the AIWS.

\section{Discussion}

In 1955, the British psychiatrist John Todd (1914-1987) described the state of micro- and macrosomatognosia, the changed perception of the body image and the body illusions, and called it the Alice in Wonderland syndrome. 1955 John Todd described the syndrome and gave it the literary name in its publication. The first description of the syndrome comes from Lippman et al. from 1952. Alice in Wonderland syndrome includes false perceptions of the body image, the shape of objects, the sense of time and illusionary visual perceptions. Illusionary body perceptions trigger fear and anxiety, sometimes for many years in early childhood, and can affect the normal development of the child in the family and his environment [1]. AIWS has been described in various publications in connection with many different infectious diseases such as malaria, zicavirus, varicella-induced optical neuromyelitis, Lyme disease, H1N1 flu infection and mononucleosis. It is evident that all of these various diseases do not play a role in the search for the true origin of Alice in Wonderland Syndrome. Other entities such as complex partial epilepsy, migraines, acute disseminated encephalomyelitis, drug abuse such as LSD or montelukast (mast cell stabilizer) are other associated drug correlations in connection with AIWS-like seizures. In addition, more recent articles describe AIWS seizures after ventriculoatrial shunt surgery in hydrocephalus postoperatively and in patients with brain cancer, especially glioblastoma. Recent publications describe the curious aspect of AIWS attacks that correlate chronically with physical abuse [2-4].

In these publications, two older women aged 57 and 61 describe their horrific experiences with sexual abuse and chronically correlated AIWS attacks after many years $[2,3,5]$. These case studies shed light on aspects of physical and sexual abuse by describing the entity that emerged many years after this strange experience of two older women analyzing their experiences as children [3]. These sensible and strange descriptions and fair descriptions of two older women from the United States and Great Britain should be supported by further cases and research [6]. The topic is very sensitive, very curious and should be analyzed with other cases. In our chronological individual case report, a 67 years-old man describes in detail his experience in childhood before age 9 with visual disturbances in form of AIWS visual impairment and physical abuse of the father. The patient described these experiences in correlation together. In conclusion, this report shed light on a further case of physical abuse and AIWS-like visual disturbances.

\section{References}

1. Cohen MN (1996) Lewis carroll: A biography, Vintage Books, New York, USA.

2. Bittmann S (2018) The clue to the unknown origin of Alice in wonderland in children? Pediatr Res Child Health 2(1): 1. 
3. Bittmann S, Luchter E, Villalon G (2018) Does sexual abuse play a causative role in Alice in wonderland Syndrome in Childhood? A help screaming from internet. J Perina Clin Pediatr 1(1): 1.

4. Bittmann S (2018) Abuse in children: Indicator of failure in relationship? Adv Pediatr Res 5: 1-2.
5. Bittmann $S$ (2018) Alice in wonderland syndrome in childhood: Abuse is the root? J Pediatr Dis 2(2): 1-2.

6. Bittmann S, Weissenstein A, Luchter E, Alieva EM, Villalon (2019) First case of Alice in wonderland-like seizures in a mother and her daughter: A new sign for a hereditary origin? Am J Biomed Sci \& Res 6(4): 301-303.

For possible submissions Click below: 